\title{
Description and molecular characterization of Chrysopilus kafkai sp. nov. (Diptera: Rhagionidae) from Serra da Bodoquena (Mato Grosso do Sul, Brazil)
}

\author{
Bianca Melo Cegolin ${ }^{1,2}$; Gabriel Marangão Bueno ${ }^{1,3}$; Gabriel Lopes Pereira ${ }^{1,4}$; Daubian Santos ${ }^{1,5}$ \& Charles Morphy Dias dos Santos ${ }^{1,6}$ \\ 1 Universidade Federal do ABC (UFABC). Santo André, SP, Brasil. \\ 2 ORCID: http://orcid.org/0000-0003-3884-931X. E-mail: biancacegolin@gmail.com \\ 3 ORCID: http://orcid.org/0000-0001-8478-4380. E-mail: gabrielmbuen010@gmail.com \\ ${ }^{4}$ ORCID: http://orcid.org/0000-0003-2330-5301. E-mail: gabriellpy@gmail.com \\ ${ }^{5}$ ORCID: http://orcid.org/0000-0003-1220-1267. E-mail: daubians@gmail.com \\ ${ }^{6}$ ORCID: http://orcid.org/0000-0001-5577-0799. E-mail: charlesmorphy@gmail.com (corresponding author)
}

\begin{abstract}
Rhagionidae (Brachycera, Tabanomorpha) is a widespread family of the order Diptera, containing ca. 720 species in 22 genera worldwide distributed. Chrysopilus Marquart is one of the most speciose genus of Rhagionidae. Here we describe Chrysopilus kafkai sp. nov. Cegolin \& Santos, the first record of a rhagionid species from Midwest Brazilian region, and includes an identification key and a distribution map to the Brazilian species of Chrysopilus. The species description is complemented by a molecular characterization of the 285 rRNA sequence.
\end{abstract}

Key-Words. 28S; Morphology; Neotropical; SISBI0TA; Taxonomy.

\section{INTRODUCTION}

Rhagionidae (Diptera: Tabanomorpha), also known as snipe flies, has approximately 720 extant species in 22 genera worldwide distributed (Santos, 2008; Kerr, 2010). The family is one of the oldest within Brachycera, dating back to the Lower Triassic (Krzeminski \& Krzeminska, 2003; Wiegmann et al., 2011). Adult rhagionids are medium to large-sized flies $(4-20 \mathrm{~mm})$, usually found in woodlands and rainforests (Kerr, 2010). The biology of the group is mostly unknown - the genus Symphoromyia Frauenfeld is reported as hematophagous, and a few other genera, such as Spania Meigen, Litoleptis Chilcott and Ptiolina Zetterstedt, have bryophyte-feeder larvae (Imada \& Kato, 2016).

Rhagionidae lacks any clear synapomorphies. The family may be identified by the absence of a scale on the postspiracular sclerite (Kerr, 2010) and by the relative position of fork $R_{4}-R_{5}$ with respect to cell $\mathrm{dm}$ and the curvatures of $R_{5}$ and $R_{4}$ (Grimaldi \& Cumming, 1999). Although molecular-based analyses, such as Wiegmann et al. (2000), suggests the family may be paraphyletic with respect to the other families of Tabanomorpha, Kerr (2010)'s extensive analysis, including both morphological and molecular analyses, depicts Rhagionidae as monophyletic.
Only four of the 22 extant genera of Rhagionidae are found in the Neotropical region: Chrysopilus Macquart 1826, Rhagio Fabricius 1805, Atherimorpha White 1914 and Sierramyia (Lindner 1924) Kerr 2010 (Santos, 2008; Kerr, 2010; González et al., 2020). Chrysopilus, diagnosed mainly by the presence of a fusion between the sternite IX and the gonocoxites, and along with features such as wing veins $R_{4+5}$ fork almost in a right angle, is the most diversified and widespread rhagionid genus (Santos \& Amorim, 2007).

Although 18 Chrysopilus species have been described in Brazil (Santos, 2008), none of them are known for the Midwest Brazilian region. Made up by the Federal District and three states (Goiás, Mato Grosso and Mato Grosso do Sul), this region holds one of the most diverse savannahs of the world, the Cerrado, and the largest tropical wetland, the Pantanal, along with some dry forest areas (IBGE, 2012). Despite its high number of endemic species (Junk et al., 2006), few collecting expeditions have been conducted in the area or used specimens collected in the two biomes. As a result, there is still an important lack of knowledge on the dipterofauna in the region.

In the present paper, we describe a new species of Chrysopilus collected during expeditions at 




Figure 1. Chrysopilus kafkai, sp. nov., male holotype. (A) Habitus sp. nov., lateral view. (B) Head: frontal view. Abbreviations: ar, arista; cl, clypeus; ff, first flagellomere; ot, ocellar tubercle; pe, pedicel; $p l$, palpus; scp, scape.

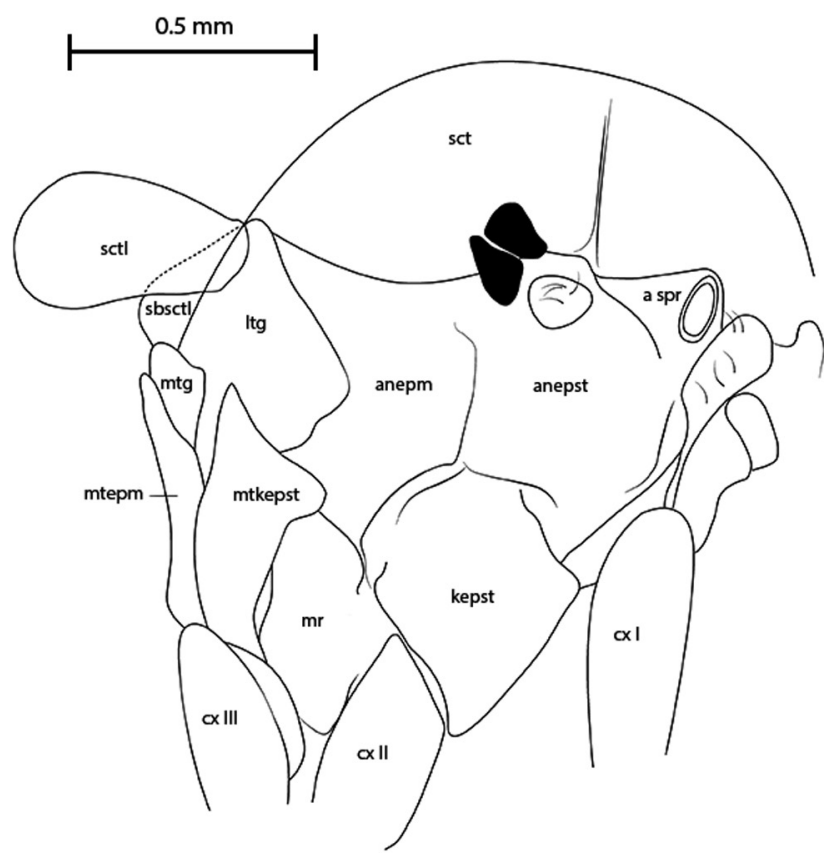

Figure 2. Thorax of Chrysopilus kafkai sp. nov., male holotype: lateral view. Abbreviations: a spr, anterior spiracle; anepm, anepimeron; anepst, anepisternum; $c x$, coxa; kepst, katepisternum; Itg, laterotergite; mr, meron; mtepm, metepimeron; $m t g$, mediotergite; mtkepst, metakatepisternum; sct, scutum; sctl, scutellum, sbsctl, subscutellum.

the Serra da Bodoquena (Mato Grosso do Sul, Brazil), a national park located in the Cerrado. These expeditions were organized by the SISBIOTA-Diptera project (Lamas et al., 2014). The new species described here is the first record of the family Rhagionidae in the Brazilian Midwest Brazilian region. The description includes both morphological and molecular data.

\section{MATERIAL AND METHODS}

\section{Taxonomy}

The morphological analysis was based on direct observation of dry material, and dissections of male and female terminalia, preserved in vials with glycerin. Illustrations were made using a Nikon Eclipse E200 optical microscope with camera lucida and then vectorized in Adobe Illustrator CS 2018. Photographs were made with a Carl Zeiss SteREO Discovery.V12 Stereo Microscope attached to a Canon EOS Rebel T2i digital camera. All deep focus images were stacked in Adobe Photoshop CS 2018. Scanning electron microscope (SEM) photographs were made using a FEI Quanta 250 scanning electron microscope. The distribution map was made in QGIS 3.6.1, based on distribution registers presented on Santos \& Amorim (2007) and Santos (2008).

All the material of the new species is now pinned and deposited in the collection of the Museu de Zoologia da Universidade de São Paulo (MZUSP).

Descriptive terminology follows Cumming \& Wood (2017). Abbreviations used in the figures were: aed, aedeagus; a spr, anterior spiracle; $a_{1}$, first anal cell; anepm, anepimeron; anepst, anepisternum; ar, arista; $b m$, basal medial cell; $b r$, basal radial cell; $C$, costal vein; $c$, costal cell; ce, cercus; cl, clypeus; cua, anterior cubital cell; cup, posterior cubital cell; $C u A$, cubital anterior vein; $C u P$, posterior branch of cubital vein; $c x$, coxa; $d$, discal cell; ej ap, ejaculatory apodeme; ff, first flagellomere; gc ap, gonocoxal apodeme; $g c$, gonocoxite; $g$ s, gonostylus; $h$, humeral vein; hyp val, hypogynial valve; kepst, katepisternum; lat ej proc, lateral ejaculatory process; Itg, laterotergite; $M$, 
medial vein; $m r$, meron; $m$ tepm, metepimeron; $m t g$, mediotergite; $m$ tkepst, metakatepisternum; $m$-cu, crossvein m-cu; $m$-m, crossvein m-m; o, ocellus; oc, occiput; ot, ocellar tubercle; par, paramere; par ap, parameral apodeme; pe, pedicel; $p l$, palpus; $p v l$, posteroventral cercal lobe; $R$, radial vein; $s$, sternite; $S c$, subcostal vein; $s c p$, scape; $s c t$, scutum; sctl, scutellum; sbsctl, subscutellum; sens org, sensorial organ; spm sac, sperm sac; $t$, tergite.

\section{Molecular sequencing}

We used the DNA extraction method proposed by Santos et al. (2018). The specimens were clarified with
Proteinase $\mathrm{K}$ preserving its external morphology. After clarification, the specimen was stored in ethanol $70 \%$. The DNasy extraction kit purchased from Qiagen was applied following manufacturer's instructions, and the solution dissolved in a final volume of $30 \mu \mathrm{L}$ (see the website protocols.io: http://doi.org/10.17504/protocols. io.kkqcuvw for the protocol used in here).

Concentration and quality of extracted DNA were determined by spectrophotometric evaluation of $1 \mu \mathrm{L}$ of sample, employing BioDrop $\mu$ LITE1. An aliquot of $2 \mu \mathrm{L}$ of each sample was analyzed by $1 \%$ agarose gel electrophoresis to verify DNA quality and quantity. Afterwards, 100 ng of each DNA sampled was submitted to PCR under conditions $72^{\circ} \mathrm{C} 7 \mathrm{~min} / 40 \mathrm{cycles}$ of $94^{\circ} \mathrm{C} 30 \mathrm{sec}, 50^{\circ} \mathrm{C}$
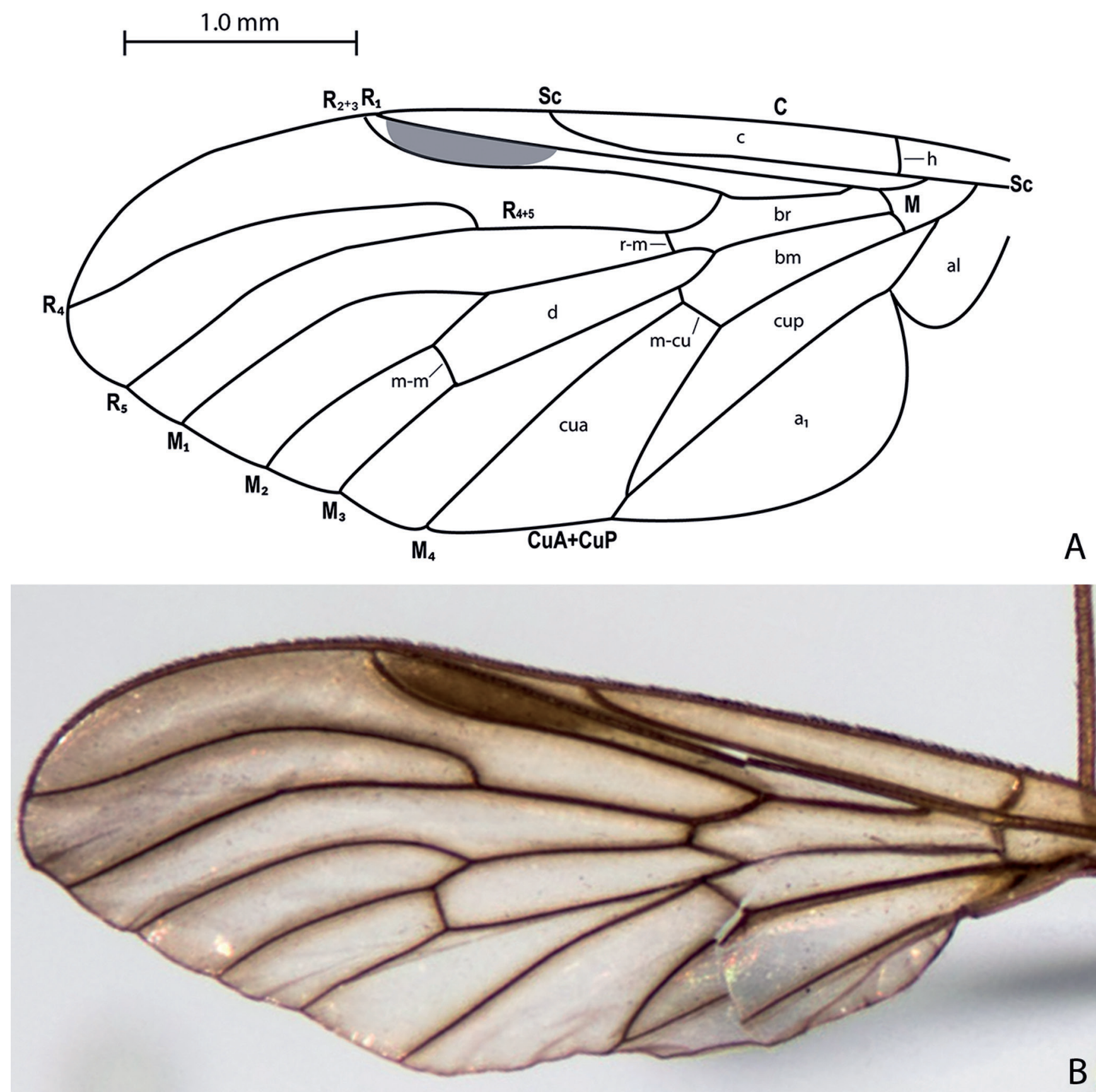

Figure 3. Wing of Chrysopilus kafkai sp. nov., male holotype. (A) Illustration. (B) Photograph. Abbreviations: al, alula; $a_{1}$, first anal cell; $b m$, basal medial cell; $b r$, basal radial cell; $C$, costal vein; $c$, costal cell; CuA, cubital anterior vein; CuP, posterior branch of cubital vein; cua, anterior cubital cell; cup, posterior cubital cell; $d$, distal cell; $h$, humeral; $M$, medial vein; $m$-cu, crossvein $\mathrm{m}$-cu; $m-m$, crossvein $\mathrm{m}$ - $\mathrm{m}$; $R$, radial vein; $r-m$, crossvein $r-\mathrm{m}$; $S c$, subcostal vein. 
$30 \mathrm{sec}, 72^{\circ} \mathrm{C} 30 \mathrm{sec} / 72^{\circ} \mathrm{C} 5 \mathrm{~min}$, with the GoTaq DNA polymerase from Promega, to amplify a 464 bp fragment corresponding to D7 fragment of the 28S rRNA encoding gene from Diptera (Tautz et al., 1988). The primers are shown in Table 1.

PCR products were analyzed by agarose gel electrophoresis stained with GelRed. The amplified products were purified with ThermoScientific PCR purification kit and submitted to Sanger's sequencing using Big Dye

Table 1. Primers of 285 ribosomal gene used in the study.

\begin{tabular}{cc}
\hline Forward primer & CTGAAGTGGAGAAGGGT \\
\hline Reverse primer & GACTTCCCTTACCTACAT \\
\hline
\end{tabular}

Terminator version 3.1 ( $\mathrm{ABI}$ foster City, $\mathrm{CA}$ ), according to manufacturer's instructions. The sequences were analyzed through the Basic Local Alignment Search Tool (BLAST) (Altschul et al., 1990).

The new sequences were deposited in GenBank (MK039530).

\section{RESULTS AND DISCUSSION}

\section{Chrysopilus Macquart}

Chrysopilus Macquart, 1826: 403. Type species, Rhagio diadema (Fabricius 1775) (Westwood, 1840: 134).
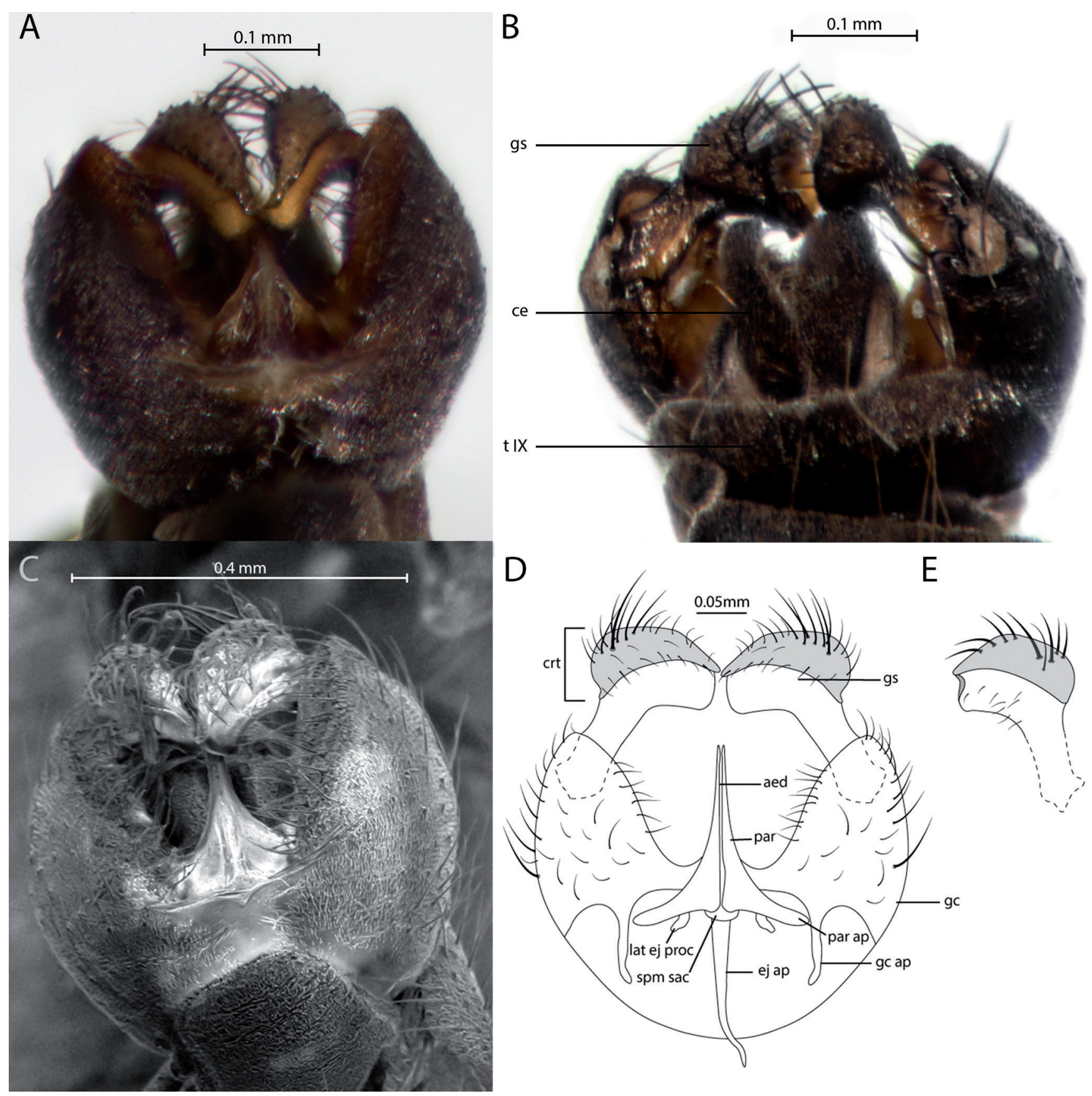

E
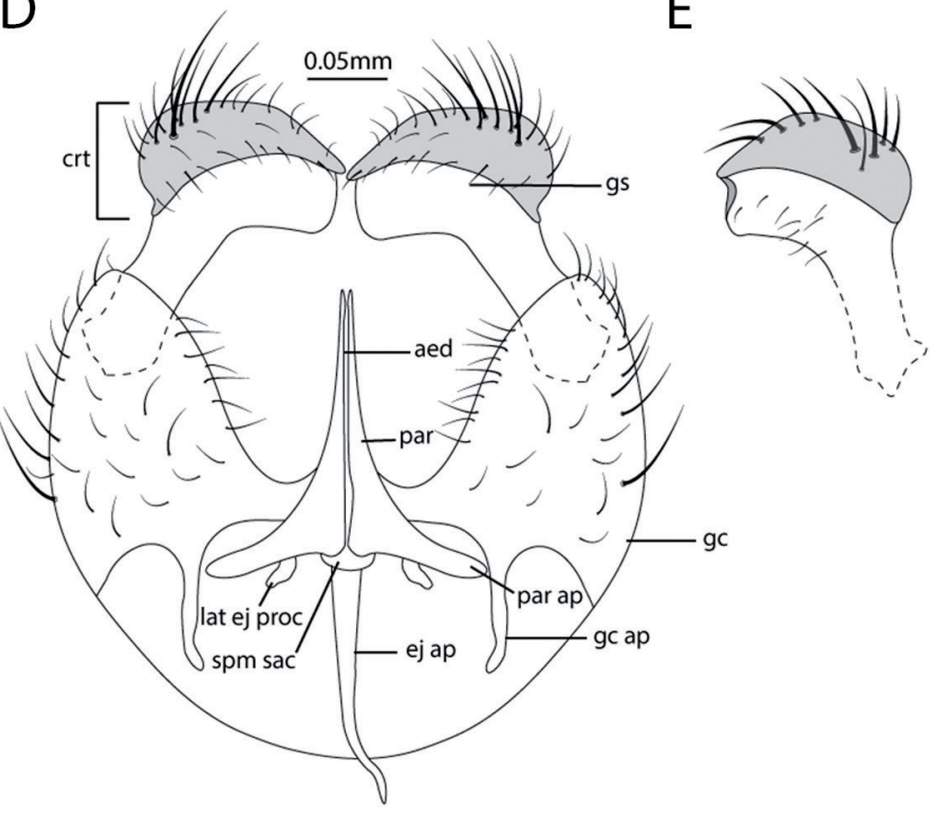

Figure 4. Terminalia of Chrysopilus kafkai sp. nov., male holotype. (A) Genital capsule, dorsal view. (B) Ventral view. Abbreviations: gs, gonostylus; ce, cercus; $t$ IX, tergite IX. (C) MEV of genital capsule, dorsal view. (D) Genital capsule, dorsal view. (E) Gonostylus, ventral view. Abbreviations: aed, aedeagus; crt, crest; ej ap, ejaculatory apodeme; gcapod, gonocoxal apodeme; $g c$, gonocoxite; gs, gonostylus; lat ej proc, lateral ejaculatory process; par ap, parameral apodeme; par, paramere; spm sac, sperm sac. 


\section{Chrysopilus kafkai Cegolin \& Santos sp. nov. Figs. 1-7}

Material: Holotype: $\sigma^{\top}$, BRAZIL, Mato Grosso do Sul, Serra da Bodoquena, $20^{\circ} 41^{\prime} 53.5^{\prime \prime} \mathrm{S}, 56^{\circ} 52^{\prime} 55.7^{\prime \prime} \mathrm{W}, 06-22$. xii.2011, Lamas, Nihei \& eq. col (MZUSP). Paratypes: $10^{\text {", }}$ Mato Grosso do Sul, Serra da Bodoquena, 20 42'15"S, $56^{\circ} 51^{\prime} 00^{\prime \prime} \mathrm{W}, 09 / \mathrm{XII} / 2011$, Lamas, Nihei \& eq. col.; 1 \%, Mato Grosso do Sul, Serra da Bodoquena, $20^{\circ} 41^{\prime} 49.9^{\prime \prime} S$, 56 $52^{\prime} 54.0^{\prime \prime} \mathrm{W}$, 22/XII/2011-06/I/2012, Lamas, Nihei \&



Figure 5. Habitus of Chrysopilus kafkai sp. nov., female. (A) Dorsal view. (B) Lateral view. (C) Head, dorsolateral view. 


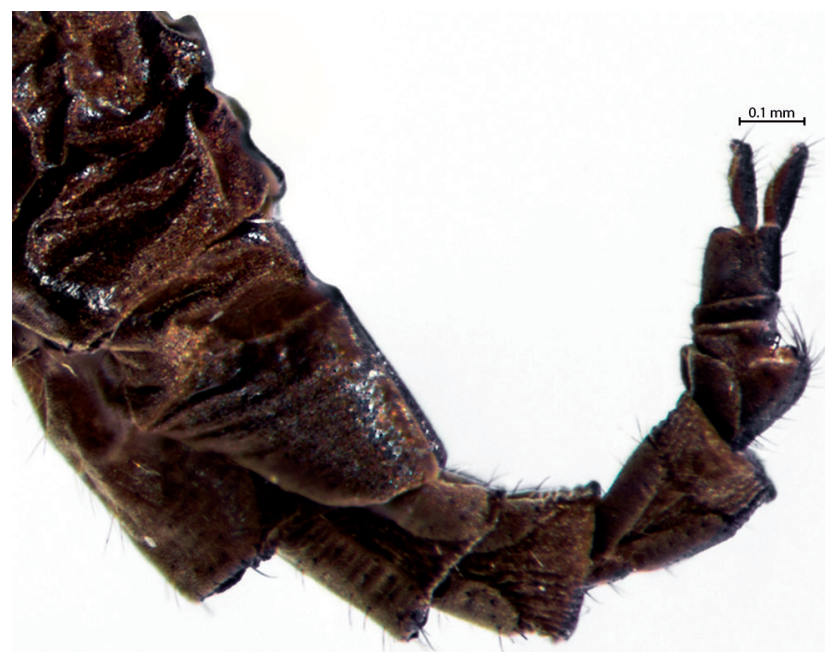

Figure 6. Female terminalia of Chrysopilus kafkai sp. nov., lateral view.

A

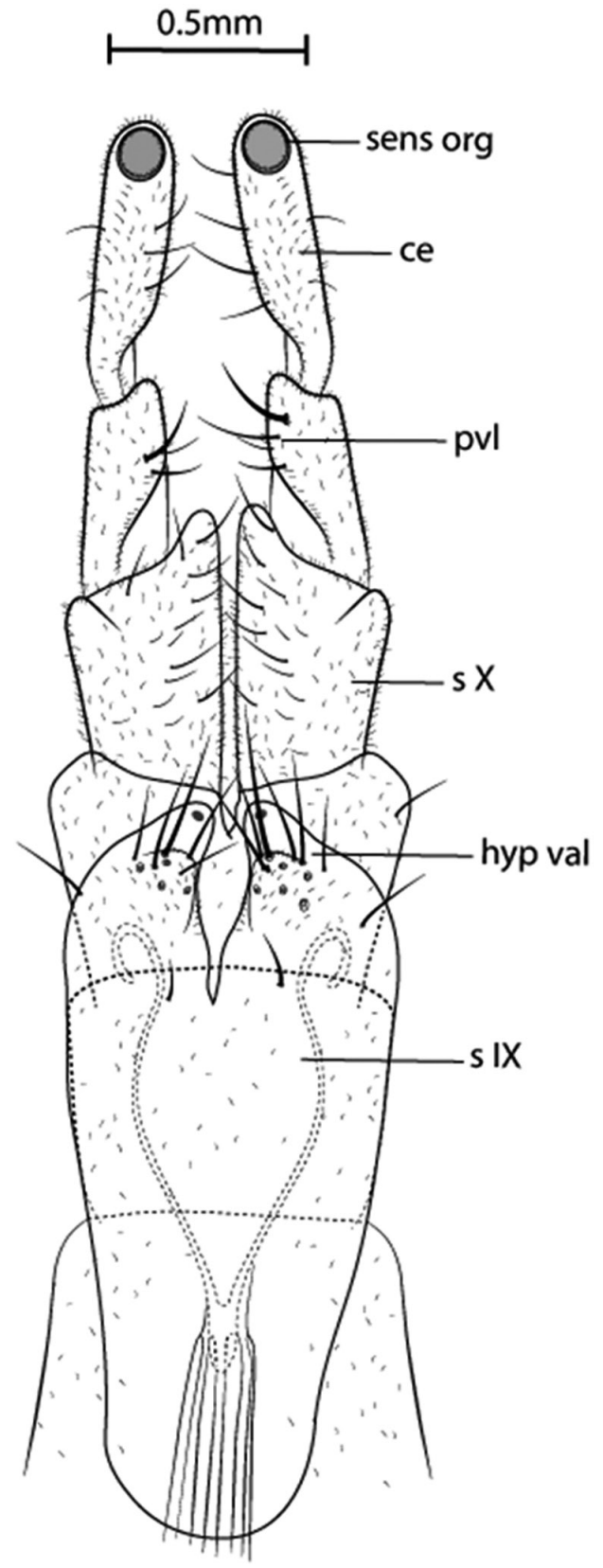

eq. col.; 1 \%, Mato Grosso do Sul, Serra da Bodoquena, $20^{\circ} 41^{\prime} 49.9^{\prime \prime} \mathrm{S}, 56^{\circ} 52^{\prime} 54.0^{\prime \prime} \mathrm{W}, 06-21 / \mathrm{XI} / 2012$, Lamas, Nihei \& eq. col. Additional material: $1 \sigma^{\circ}$, Mato Grosso do Sul, Serra da Bodoquena, 2041'53.5"S, 5652'55.7"W, 06-22/ XII/2011, Lamas, Nihei \& eq. col.; 1 \&, Mato Grosso do


XII/2011, Lamas, Nihei \& eq. col.; $10^{\prime \prime}$, Mato Grosso do Sul, Serra da Bodoquena, 2041'49.9"S, 56 52'54.0"W, 22/XII/2011, Lamas, Nihei \& eq. col.; 1 \&, Mato Grosso do Sul, Serra da Bodoquena, 2041'49.9"S, 56 52'54.0"W, 21/ I/2012-05/II/2012, Lamas, Nihei \& eq. col.; $10^{\prime \prime}$, Mato Grosso do Sul, Serra da Bodoquena, 2041'49.9"S, 5652'54.0"W, 05-20/II/2012, Lamas, Nihei \& eq. col.; $1 \sigma^{7}$, Mato Grosso do Sul, Serra da Bodoquena, 2041'55.9"S, 5652'49.4"W, 21/IX/2012-06/XI/2012, Lamas, Nihei \& eq. col.; 1 o", Mato Grosso do Sul, Serra da Bodoquena, 2041'49.9"S, 56 52'54.0"W, 06-21/XII/2012, Lamas, Nihei \& eq. col.

B

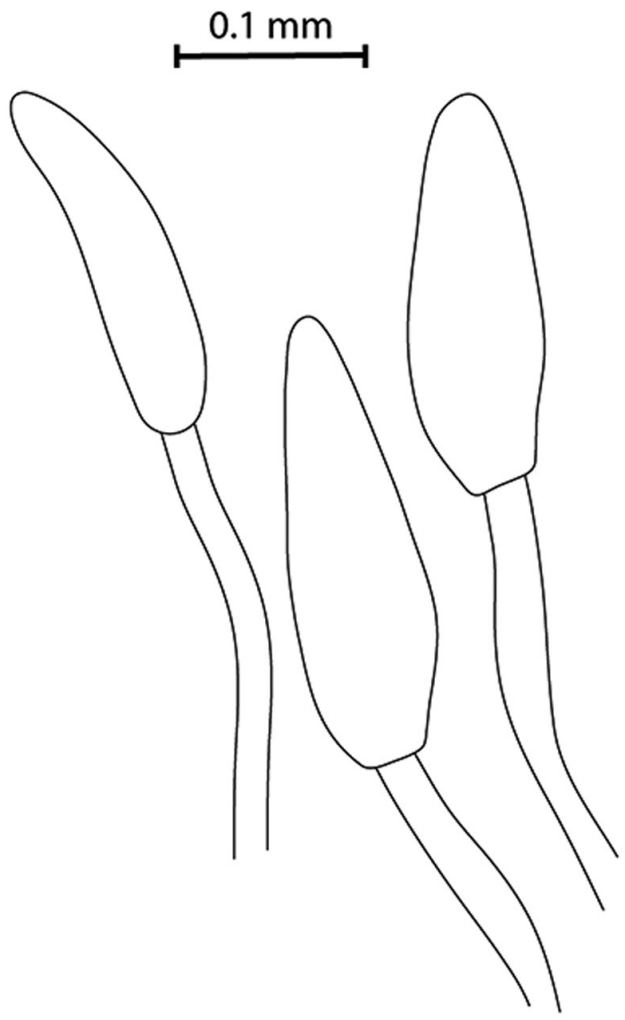

Figure 7. (A) Female terminalia of Chrysopilus kafkai sp. nov. (B) Spermathecae. Abbreviations: ce, cercus; hyp val, hypogynial valve; pvl, posteroventral cercal lobe; sIX, sternite IX; sens org, sensorial organ. 
Preservation: Holotype and paratypes dry and well preserved, with a few imperfections; additional material in $70 \%$ alcohol, with some missing parts, but complete enough to be identified as the new species.

Diagnosis: Gonostylus crest dark brown, strongly curved distally with thick long setae (Fig. 4), yellowish brown anteriorly. Another diagnose characteristic is the wing non-hyaline with only the middle of $r_{3}$ and $r_{4}$ cells lighter than the borders (Fig. 3).

Male (Figs. 1-4): length: body ca. $6.5 \mathrm{~mm}$, wing ca. $7.3 \mathrm{~mm}$. General color dark brown (Fig. 1a). Head in shades of brown (Fig. 1b). Eyes holoptic, slightly grayish brown with the borders in blackish brown, ommatidium facets round; ocellar tubercle dark brown, ocellus light brown. Gena brown, lighter than the eyes. Bare and strongly curved clypeus. Antenna uniformly light brown with short thin setae, 1.6 times smaller than head; scape flattened, pedicel two times longer than scape, first flagellomere tapering toward apex, clearly narrower than pedicel and approximately as wide as scape. Maxillary palpus light brown, distally angled with thick medium-sized setae. Proboscis yellowish brown. Occiput grayish brown, with long-sized setae.

Thorax dark brown (Fig. 1a), wider than long. Meron almost two times wider than long, katepisternum almost as wide as high (Fig. 2). Coxa dark brown, femur, tibia, and tarsus light yellow (Fig. 1a). Wing membrane brownish along most veins (Fig. 3); pterostigma, approximately six times smaller than the wing length; $R_{1}$ and $R_{2+3}$ running parallel for the most part, only last third of $\mathrm{R}_{2+3}$ converging towards $R_{1} ; R_{4}$ barely curved; CuA and CuP joining far from wing margin, $\mathrm{CuA}+\mathrm{CuP}$ as long as $\mathrm{r}-\mathrm{m}$ crossvein; discal cell approximately $4.2 x$ longer than wide, bm cell five times longer than wide, br cell six times longer than wide, cua cell six times longer than wide, c cell placed before pterostigma; alula broad. Halter light brown (Fig. 1a).

Abdomen dark brown (Fig. 1a). Gonocoxite dark brown with long setae; gonostylus apex dark brown, protruding curved crest with long setae (Fig. 4), bottom yellowish brown; gonostylus with a distal concavity (Fig. 4e). Aedeagus long, half the gonocoxite length (Fig. 4). Ejaculatory apodeme long, nearly as long as aedeagus. Gonocoxal apodeme approximately half of the aedeagus length; parameral apodeme short, do not extending beyond the gonocoxal apodeme; lateral ejaculatory process short. Cercus dark brown with short setae, distancing each other distally (Fig. 4b).

Female (Figs. 5-7): Same as males, except as follows: length: body $7.8 \mathrm{~mm}$, wing $7.3 \mathrm{~mm}$. Eyes dichoptic.

Cercus dark brown, two-segmented with slightly rounded apex in the distal segment (Fig. 6), posteroventral cercal lobe two times longer than wide (Fig. 7a). Sternite VIII slightly rounded anteriorly; hypogynial

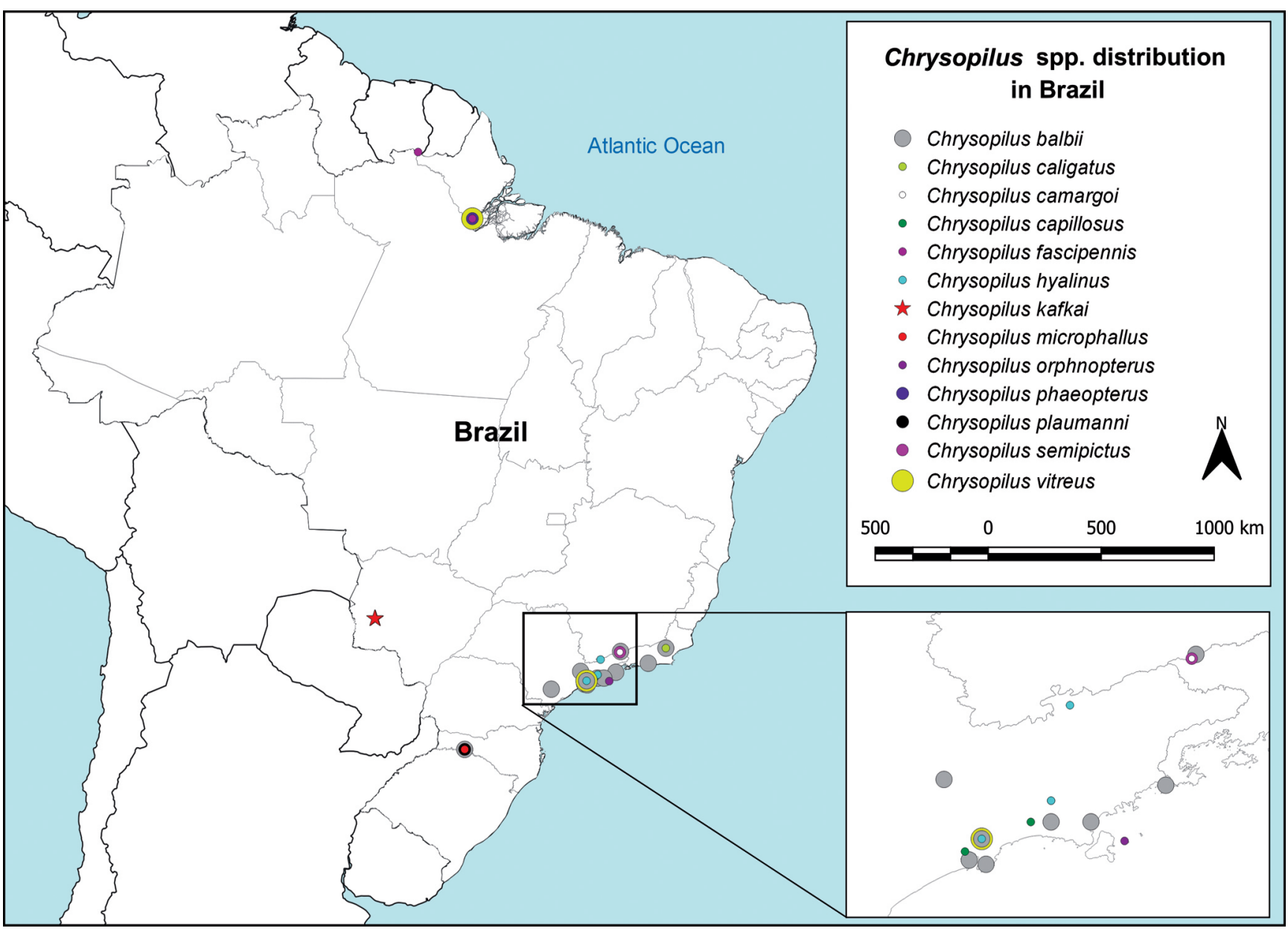

Figure 8. Distribution map of Brazilian species of Chrysopilus. 

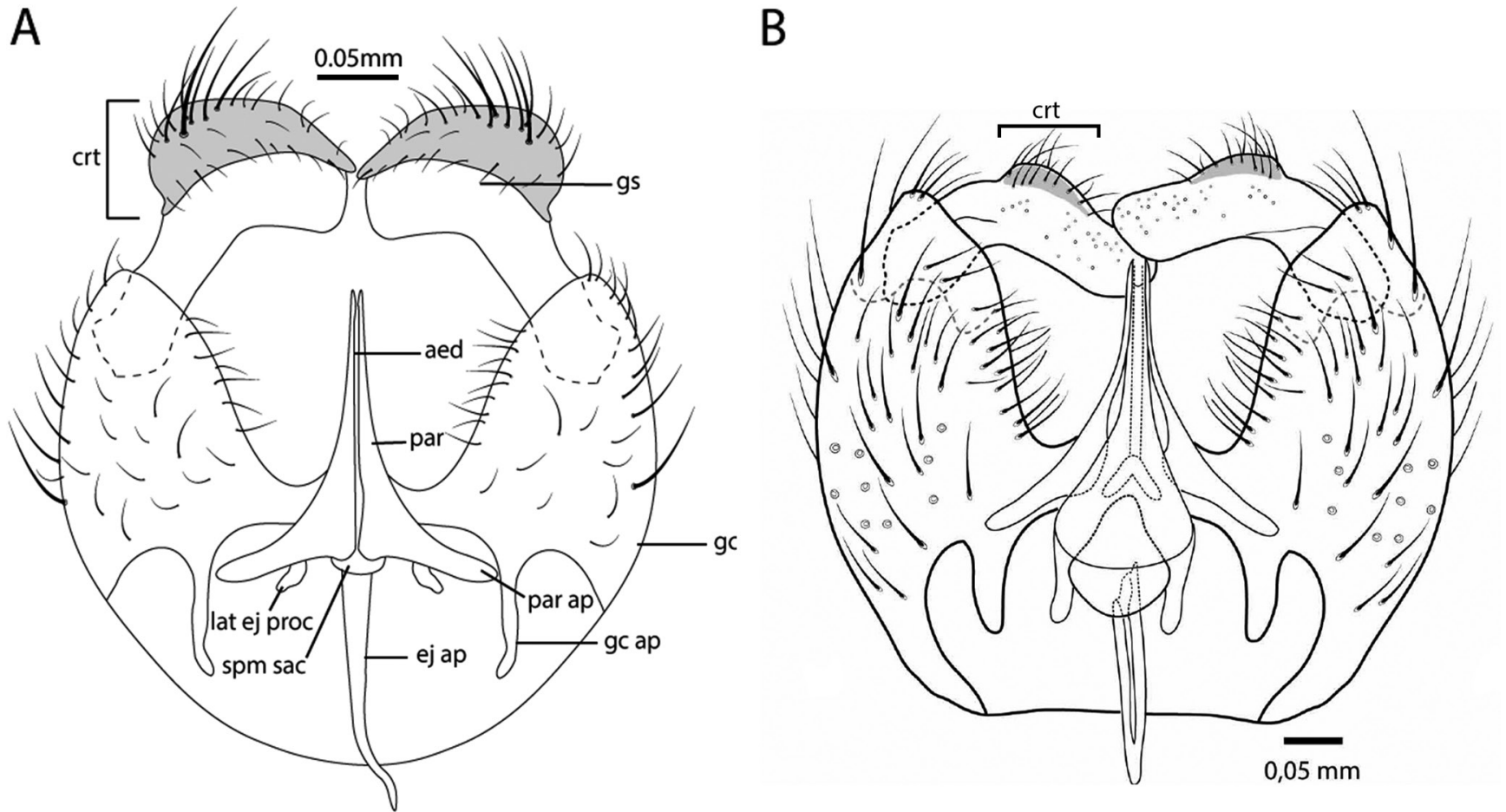

Figure 9. Comparison between gonostylus crests: (A) Chrysopilus kafkai and (B) Chrysopilus plaumanni.

valves with long and thick setae (Fig. 7a); genital fork with a slightly elongated anterior protrusion and distal short apodemes. Three spermathecae oblong (Fig. 7b).

Geographic distribution: Serra da Bodoquena, state of Mato Grosso do Sul, Midwest Brazilian region (Fig. 8).

Etymology: Based on its general dark color, the species is named after the fiction author Franz Kafka, whose literature mostly deals with the darkness and absurdity of human behavior.
Comments: Chrysopilus kafkai sp. nov. resembles Chysopilus plaumanni Santos \& Amorim in the general aspect of the male terminalia. However, C. kafkai sp. nov. has a distinctive crest occupying almost half of the gonostylus, while the crest in C. plaumanni is restricted to the distal region of the gonostylus (Fig. 9).

Our molecular characterization of 28S rRNA of Chrysopilus kafkai sp. nov. expands the geographical representation of molecular data for the genus, now with sequences from species distributed in three biogeographical regions (Nearctic, Neotropical, and Australian).

\section{Key to the Brazilian species of Chrysopilus}

This key is adapted from Santos \& Amorim (2007) and includes Chrysopilus kafkai sp. nov.

1. Wing completely hyaline except for pterostigma

- Wing non-hyaline (with at least part of the membrane grayish to brown fumose)

2. Ejaculatory apodeme short, not reaching or exceeding the anterior margin of the terminalia (Southern Brazil)... Chrysopilus marumbiensis Coscarón \& Coscarón

- Ejaculatory apodeme long, reaching or exceeding the anterior margin of the terminalia.

3. Apex of $\mathrm{R}_{4}$ straight, without distal curvature; small pterostigma; gonocoxal apodemes long, almost reaching the base of the gonocoxite (Southeastern Brazil). ..Chrysopilus hyalinus Santos \& Amorim

- Apex of $R_{4}$ with slight distal curvature; wide pterostigma, reaching $C$; gonocoxal apodeme far from the base of the gonocoxite (Guyanian Shield)

Chrysopilus vitreus Santos \& Amorim

4. Wing about three times longer than wide

- Wing about two times longer than wide.

5. Apex of gonostylus acuminate; wing membrane light brown, darker apically and along some basal veins; $\mathrm{R}_{4+5}$ fork angle smaller than $90^{\circ}$; wide stigmal spot, reaching $R_{2+3}$, Costal, and subcostal cell; ejaculatory and gonocoxal apodemes not exceeding the anterior margin of the terminalia (Southern Brazil).

- Apex of gonostylus truncated; wing membrane homogeneously brownish; $R_{4+5}$ fork almost in a right angle; small stigmal spot, not reaching $R_{2+3}$ or Costal cell; ejaculatory and gonocoxal apodemes exceeding the anterior margin of the genitalia (Guyanian Shield)

Chrysopilus phaeopterus Santos \& Amorim

- Apex of gonostylus truncated; wing membrane homogeneously brownish; $\mathrm{R}_{4+5}$ fork almost in a right angle; small stigmal spot, not reaching $\mathrm{R}_{2+3}$ or Costal cell; ejaculatory and gonocoxal apodemes long, both exceeding the anterior margin of the genitalia (Guyanian Shield)...Chrysopilus phaeopterus Santos \& Amorim

6. Wing with a distinctive dark brown apical band (Southeastern Brazil). Chrysopilus semipictus Santos \& Amorim 
- Wing without a distinctive dark brown apical band 7

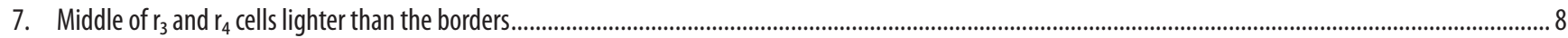

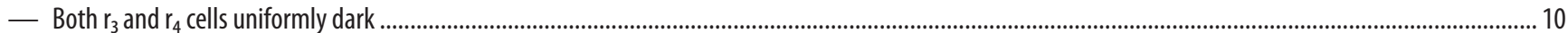

8. Beginning of $\mathrm{M}_{2}$ shorter than $\mathrm{m}-\mathrm{m}$; gonostylus without a crest .......................................................................................Chrysopilus balbii Santos \& Amorim

- Beginning of $\mathrm{M}_{2}$ longer than $\mathrm{m}-\mathrm{m}$; gonostylus with a crest

9. Discal cell ca. 4.5 times longer than wide; gonostylus slightly swollen (Fig. 9b) (Southern Brazil)

Chrysopilus plaumanni Santos \& Amorim

— Discal cell ca. 4.0 times longer than wide; gonostylus strongly curved distally (Fig. 9a) (Midwest Brazil) Chrysopilus kafkai sp. nov.

10. Wing with distinctive dark brown distal band

11

- Wing without distinctive dark brown distal band...

13

11. Wing dark brown distal to front of radial but not on medial crossveins; gonostylus long (Southeastern Brazil)

- Wing dark brown distal to front of radial and medial crossveins; gonostylus short

Chrysopilus camargoi Santos \& Amorim

12. CuA and CuP joining far from wing margin, gonostylus subtrapezoidal (Southern Brazil)

- CuA and CuP joining near from wing margin, swollen acuminated distally (Southeastern Brazil)

Chrysopilus consanguineus Schiner

13. $R_{2+3}$ reaching Costal vein merging with $R_{1}$ (Amazonian Basin) Chrysopilus orphnopterus Santos \& Amorim

- $R_{2+3}$ reaching C not verging with $R_{1}$ Chrysopilus fascipennis Bromley

14. Gonostylus long, distally acuminate, with strong basal bristles (Southeastern Brazil) ... 14

— Gonostylus swollen, slightly rounded distally, without strong basal bristles (Southeastern Brazil)

Chrysopilus capillosus Santos \& Amorim ..Chrysopilus caligatus Santos \& Amorim

\section{CONCLUSION}

Until the description of Chrysopilus kafkai sp. nov., just over a dozen of species of Rhagionidae were known to Brazil, concentrated in the Amazon basin and the Brazilian Atlantic Forest (Santos \& Amorim, 2007; Santos, 2008). Despite containing a unique and diversified biome - the Cerrado - the biodiversity of the Midwest Brazilian region is still poorly known (Junk et al., 2006). The lack of knowledge on the species of Diptera in the states of Mato Grosso, Mato Grosso do Sul and Goiás is significant (Lamas et al., 2014). Any new species description in a poorly known area such as the Midwest Brazilian region is important to diminish the knowledge gap about biological diversity in the Neotropics. As seen in the distribution map, there is a remarkable absence of species of Chrysopilus described for the Midwest Brazilian region, probably due to lack of published studies, since the region is a hotspot for a number of insect species (Junk et al., 2006; Lamas et al., 2014). Furthermore, the fact that C. kafkai sp. nov. is the first record of such a widespread family as Rhagionidae in the second largest region in Brazil shows the need for increasing taxonomic efforts for documenting the Brazilian dipterofauna. There may be a vast diversity of species of Diptera, including rhagionids and other Tabanomorpha, waiting for formal description.

\section{ACKNOWLEDGEMENTS}

The authors would like to thank Stephanie Sampronha and Max M. Fuhlendorf for suggestions, the CEM-SBC (UFABC) team for helping with the MEV pictures, and Dr. Marcia Ap. Sperança and the Laboratory of Pathogenic Agents (UFABC) for laboratorial support. We would also thank Carlos Lamas (MZUSP) for the loan of the Rhagionidae specimens collected within the SISBIOTA Project, supported by the Conselho Nacional de Desenvolvimento Científico e Tecnológico (CNPq) (Proc. № 563256/2010-9) and Fundação de Amparo à Pesquisa do Estado de São Paulo (FAPESP) (Proc. № 2010/52314-0).
This study was financed in part by the Coordenação de Aperfeiçoamento de Pessoal de Nível Superior - Brazil (CAPES) - Finance Code 001. Financial support was also provided by CNPq (455858/2014-4; 305630/2016-4; $307662 / 2019-5)$ and FAPESP (2016/14514-4) (GLP), (2017/11768-8) (CMDS), (2018/16305-6) (DS).

\section{AUTHOR CONTRIBUTIONS}

BMC and CMDS conceived the paper, described the new species and led the writing. GLP and GMB sequenced the $28 \mathrm{~S}$ ribosomal gene of the new species, collected the molecular data and performed a phylogenetic analysis to test the positioning of $C$. kafkai. DS prepared the material for the species description and the identification key. All authors reviewed the final manuscript.

\section{REFERENCES}

Altschul, S.F.; Gish, W.; Miller, W.; Myers, E.W. \& Lipman, D.J. 1990. Basic local alignment search tool. Journal of molecular biology, 215(3): 403-10.

Cumming, J.M. \& Wood, D.M. 2017. 3. Adult morphology and terminology. In: Kirk-Spriggs, A.H. \& Sinclair, B.J. (Eds.). Manual of Afrotropical Diptera. Volume 1. Introductory chapters and keys to Diptera families. Suricata 4. Pretoria, South African National Biodiversity Institute. p. 21-65.

González, C.R.; Elgueta, M. \& Santos, C.M.D. 2020. A catalog of Rhagionidae (Diptera: Brachycera) from Chile. Zootaxa, 4728(2): 237-248.

Grimaldi, D. \& Cumming, J. 1999. Brachyceran Diptera in Cretaceous ambers and Mesozoic diversification of the Eremoneura. Bulletin of the American Museum of Natural History, 239: 1-124.

Imada, Y. \& Kato, M. 2016. Bryophyte-Feeders in a Basal Brachyceran Lineage (Diptera: Rhagionidae: Spaniinae): Adult Oviposition Behavior and Changes in the Larval Mouthpart Morphology Accompanied with the Diet Shifts. PLOS ONE, 11(11): e0165808. DOI

Instituto Brasileiro de Geografia e Estatística (IBGE). 2012. Manual técnico da vegetação brasileira. Rio de Janeiro, IBGE. 276p.

Junk, W.J.; Cunha, C.N.; Wantzen, K.M.; Petermann, P.; Strussmann, C.; Marques, M.I. \& Adis, J. 2006. Biodiversity and its conservation in the Pantanal of Mato Grosso, Brazil. Aquatic Sciences, 68: 278-309. D0I 
Kerr, P.K. 2010. Phylogeny and classification of Rhagionidae, with implications for Tabanomorpha (Diptera: Brachycera). Zootaxa, 2592(1): 1-133.

Krzeminski, W. \& Krzeminska, E. 2003. Triassic Diptera: descriptions, revisions and phylogenetic relations. Acta Zoologica Cracoviensia, 46: 153-184.

Lamas, C.; Nihei, S.; Melo-Patiu, C.; Couri, M.; Maia, V.; Carvalho, C.J.B.; Amorim, D.S.; Silva, V.C.; Ribeiro, G.; Santos, C.M.D.; Mendes, H.; Shimabukuro, P.; Urso-Guimarães, M.V.; Sallum, M.A.; Pujol-Luz, J.R.; Pujol-Luz, C.; Henriques, A.; Bravo, F.; Ale-Rocha, R.; Rafael, J.A.; Oliveira, F.; Graciolli, G.; Roque, F.; Mello, R.; Marinon, L.; Falaschi, R.L.; Wiedenbrug, S.; Capellari, R.S.; Oliveira, S.S.; Fusari, L. \& Conti, C. 2014. The SISBIOTA-Diptera Brazilian network. A long term survey of Diptera from unexplored central areas of Brazil. In: International Congress of Dipterology, 80. Abstracts. Potsdam. p. 195-196.

Macquart, J. 1826. Insectes diptères du nord de la France. Asiliques, bombyliers, xylostomes, leptides, stratiomyides, xylophagites et tabaniens. Lille, Imprimerie de L. Danel. 176p.

Santos, C.M.D. 2008. Geographical distribution of Tabanomorpha (Diptera, Brachycera): Athericidae, Rhagionidae, Vermileonidae, and small families. EntomoBrasilis, 1: 43-50. D0I

Santos, C.M.D. \& Amorim, D.S. 2007. Chrysopilus (Diptera: Rhagionidae) from Brazil: redescription of Chrysopilus fascipennis Bromley and description of eleven new species. Zootaxa, 1510: 1-33.
Santos, D.; Ribeiro, G.C.; Cabral, A.D. \& Sperança, M.A. 2018. A non-destructive enzymatic method to extract DNA from arthropod specimens: Implications for morphological and molecular studies. PLOS ONE, 13(2): e0192200. D0I

Tautz, D.; Hancock, J.M.; Webb, D.A.; Tautz, C. \& Dover, G.A. 1988. Complete sequences of the rRNA genes of Drosophila melanogaster. Molecular Biology and Evolution, 5(4): 366-376.

Westwood, J.0. 1840. An introduction to the modern classification of insects. Synopsis of the genera of British insects. London, Longman, Orme, Brown, Green and Longmans. 587p.

Wiegmann, B.M.; Trautwein, M.D.; Winkler, I.S.; Barr, N.B.; Kim, J.W.; Lambkin, C.; Bertone, M.A.; Cassel, B.K.; Bayless, K.M.; Heimberg, A.M.; Wheeler, B.M.; Peterson, K.J.; Pape, T.; Sinclair, B.J; Skevington, J.H.; Blagoderov, V.; Caravas, J.; Kutty, S.N.; Schmidt-Ott, U.; Kampmeier, G.E.;Thompson, F.C.; Grimaldi, D.A; Beckenbach, A.T.; Courtney, G.W.; Friedrich, M.; Meier, R. \& Yeates, D.K. 2011. Episodic radiations in the fly tree of life. Proceedings of the National Academy of Sciences, 108(14): 5690-5695. D0I

Wiegmann, B.M.; Tsaur, S.C.; Webb, D.W.; Yeates, D.K. \& Cassel, B.K. 2000. Monophyly and relationships of the Tabanomorpha (Diptera: Brachycera) based on 285 ribosomal gene sequences. Annals of the Entomological Society of America, 93(5): 1031-1038. D01 